\title{
Postura e Articulações: Fisioterapia e Epistemologia
}

\section{Posture and Joints: Physiotherapy and Epistemology}

Luís Filipe dos Santos Coelho ${ }^{1 *}$

PALAVRAS-CHAVE: Articulações; Postura

KEYWORDS: Joints; Posture

O trato das articulações, em especial da condição degenerativa, faz apelo a modelos de "causa-efeito" que dualizam a Fisioterapia e a caracterizam epistemologicamente. Identificá-los é antecipar a unidade, tanto da arte como da ciência.

Relativamente, então, às artroses, existe a tentação de as relacionar causalmente (ou, pelo menos, correlativamente) com as características de alinhamento articular e de (potencial) encurtamento miofascial. Analiticamente, atemos o caso da meta-análise de Tanamas et al, ${ }^{1}$ respeitante ao alinhamento da articulação do joelho. Globalmente, é o próprio paradigma "postural" que sugere que os excessos da musculatura tónica e anti-gravítica contribuem para tolher as articulações. ${ }^{2-5}$
Segundo o modelo de Mézières, ${ }^{2}$ a musculatura postural comporta-se sinergicamente como um só músculo, lordosando, parcial ou totalmente, a partir da(s) cadeia(s) muscular(es) posterior(es), num misto de "lordose + rotação interna dos membros + bloqueio diafragmático". Assume-se que os músculos e fáscias agem como tirantes osteoarticulares, influenciando o alinhamento. ${ }^{2-5}$ A partir daqui, especulou-se, muitas vezes, que os desequilíbrios musculares implicariam o desalinhamento. $\bigcirc$ caso da escoliose é paradigmático, 4,6 impondo uma desarmonia na relação com os membros. Mas há, também, a clássica associação entre hiperlordose lombar e hiperlordose cervical, com a hipercifose dorsal a corresponder, porventura, a uma curvatura meramente aparente. ${ }^{2,5}$ Para além das zonas de promontório da co- 
luna, as articulações dos ombros poderão ser sujeitas a uma maior pressão com tal "postura". De igual maneira, associa-se a hiperlordose lombar a um maior risco de desenvolvimento de coxartrose. E se a articulação da anca está afetada, também a do joelho e o pé poderão ser afetados. Mas haverá, decerto, casos, em que a perturbação parecerá "ascendente", com a posição do pé a influenciar todo o corpo. 3,6

Esta incerteza em termos de ordem de surgimento das "compensações" poderá complexificar o que se projeta enquanto abordagem "postural". Nunca se poderá ter a certeza de qual é a "origem" da deformidade, se é que a mesma é alcançável. Por outro lado, todas as pressuposições em causa são dificilmente demonstráveis empiricamente, como difícil é demonstrar a cabal eficácia da "reeducação postural", em parte porque lidamos com um aglomerado complexo de variáveis que se organizam ao longo de muitos anos. A abordagem "postural" coloca a tónica no alongamento miofascial, é "causacional" e "teorética", não podendo, comummente, escusar-se o aparecimento de novas compensações ou desarmonias (que podem resultar da/na migração dos sintomas, mal cerzidos por uma intervenção de efeito pouco significativo). Por sua vez, a abordagem empírica, mais localizacional e biomecânica, centra-se na mobilidade (incluindo terapia manual) e fortalecimento, isto sem contar com os métodos diretamente anti-sintomáticos. A eficácia é vera, mas é possível que, mais uma vez, se exporte uma compensação (em parte, precisamente porque se cala o sintoma).

Na medida em que o modelo "causativo" assenta, fortemente, numa confiança pré-científica, e dialética, em pré-noções observacionais (Francis Bacon7), que poderá, aliás, placebetizar tanto o terapeuta quanto o paciente, o modelo empírico sugere outro rigor. Mas, dado o que dissemos, a intervenção não poderá deixar de compatibilizar ambos os paradigmas, com o primeiro a ser esgrimido sem excessos, focado na "estrutura" a longo prazo, e, sobretudo, preparando, a curto prazo, o segundo. Assim, poderá a articulação ser mobilizada após "alongada", e só depois "reforçada". ${ }^{5}$ É certo que o modelo empírico desconfia do alongamento (porque pode desestabilizar a articulação) do mesmo modo que o modelo teorético desconfia do fortalecimento (sugerindo que este reforça, indiretamente, a musculatura tónica), pelo que a compatibilização dos paradigmas deve assestar numa "racionalização", que assenta, necessariamente, na condução "fenomenológica" do raciocínio clínico. Há, assim, que alongar o próprio dogma, a compensação, escusando a forçosidade do trabalho analítico, evoluindo do global para o proximal (perfilhando certa estabilidade ou previsibilidade "placebetária"/"paliativa" do acontecimento postural versus sintomático, em torno de uma abordagem científica, incluindo o terapeuta, que partilha toda a dinâmica corpo-mente), não esquecendo a síntese, no formato do equilíbrio neuromotor, que, "posturalmente", passa, precisamente, por alongar os músculos posteriores e reforçar os anteriores. ${ }^{5,6}$

\section{RESPONSABILIDADES ÉTICAS}

CONFLITOS DE INTERESSE: Os autores declaram não possuir conflitos de interesse.

SUPORTE FINANCEIRO: O presente trabalho não foi suportado por nenhum subsídio ou bolsa.

PROVENIÊNCIA E REVISÃO POR PARES: Não comissionado; revisão externa por pares.

\section{ETHICAL DISCLOSURES}

CONFLICTS OF INTEREST: The authors have no conflicts of interest to declare.

FINANCIAL SUPPORT: This work has not received any contribution grant or scholarship.

PROVENANCE AND PEER REVIEW: Not commissioned; externally peer reviewed.

\section{REFERÊNCIAS}

1. Tanamas S, Hanna F, Cicuttini F, Wluka A, Berry P, Urquhart $D$. Does knee malalignment increase the risk of development and progression of knee osteoarthritis? A systematic review. Arthritis Rheum. 2009;61;4:459-7. doi: 10.1002/art.24336.

2. Mézières F. La révolution en gymnastique orthopédique. Paris: Vuibert; 1949

3. Bricot B. Posturologia. $3^{\mathrm{a}}$ ed. São Paulo: Ícone Editora; 2004.

4. Massada L. O homem é um animal assimétrico. Especulação sobre um estudo antropométrico efectuado em jovens atletas. Lisboa: Editorial Caminho; 2006.

5. Coelho L. O anti-fitness ou o manifesto anti-desportivo. Introdução ao conceito de reeducação postural. Quinta do Conde: Contra-Margem; 2008.

6. Souchard Ph-E. Le champs clos. Paris: Maloine; 1981.

7. Bacon F. Novum organum. Porto: Rés; 1620. 